\title{
Implementation of modeling elements and 3D printing technology for chemical objects in the educational process within the framework of the «University - School» interaction system
}

\author{
N.V. Zolotareva ${ }^{1 *}, A . S$. Resnyanskaya ${ }^{2}$, and Yu.A. Ocheredko ${ }^{3}$ \\ ${ }^{1}$ Astrakhan State University, Astrakhan, Russia \\ ${ }^{2}$ Astrakhan State University, Astrakhan, Russia \\ ${ }^{3}$ Astrakhan State University, Astrakhan, Russia
}

\begin{abstract}
The article describes the experience of mutually beneficial cooperation of educational institutions in the framework of the interaction system "University - School" on the example of chemical education. The article describes in detail the stages of preparation and implementation of modern technological tools - elements of modeling and 3D printing in the educational process with the participation of schoolchildren and senior students of bachelor's and master's degrees. The considered model of interaction increases the effectiveness of the teacher's career guidance, so, in the process, the key tasks are implemented: a) introducing students to the skills of chemical modeling and practical application; b) improving teachers, reloading knowledge, skills and abilities in explaining basic concepts; c) practice-oriented training of senior students. It is established that the introduction of $3 \mathrm{D}$ printing technology in chemical education makes it possible to simplify the explanation of complex sections and eliminate the tension in the assimilation of new material. The article presents implemented examples of 3D-printed models created by schoolchildren under the guidance of students and teachers. The stages of preparation of materials, software, switching from 2D to 3D model of the object and direct printing on a 3D printer take up most of the time.
\end{abstract}

\section{A problem statement}

The education system in the XXI century is undergoing various, sometimes bizarre transformations, both in the structure of secondary and higher education. Ideally, the model of the education system is a single organically coordinated mechanism of interaction of all fundamental departments (preschool institutions, schools, colleges, universities, etc.). And, only in this case, the maximum results are achieved with the effective work of institutions. However, the real model of the education system is much more vulnerable to the inevitable differences at the boundaries of institutional structures. In this case, only comprehensive

\footnotetext{
*Corresponding author: prof-ped.gpa@mail.ru
} 
measures can minimize losses. Secondary and higher educational institutions should learn to listen to each other and develop mutually beneficial forms of cooperation in key areas [14].

The widespread informatization and equipping of educational organizations with computers, the Internet, 3D printers and virtual reality devices leads to the improvement of methodological recommendations and the development of new forms of education [5-7].

Modeling and 3D printing technologies have already made some progress in education abroad [8-11]. In Russia, there is also a steadily growing interest in the use of technological tools and applied programs in the field of education [12-14]. This paper presents the experience of implementing visualization elements and 3D printing technology of model objects in the educational process on the example of extracurricular work with students of grades 9 and 11 on the basis of a higher educational institution.

\subsection{The objective of the work}

Within the framework of the "University - School" interaction system, it is possible to implement key tasks related to practice-oriented training of undergraduate and graduate students, improving chemistry teachers, as well as introducing students to the skills of chemical modeling. Unfortunately, many teachers, as well as parents, note that when learning new material, students have difficulties in understanding complex terms or in formulating and interpreting the laws of chemistry [15-18].

Ball-rod models that have existed for a long time allowed schoolchildren to clearly see the structure of atoms and molecules $[19,20]$. These types of kits are still applicable in school education, however, such molecular modeling kits do not solve all the problems that the teacher faces when explaining the material. To achieve the pedagogical goal, there is a need to use additional tools to help the student not only understand the basic concepts of chemistry, but also to see the connection in related disciplines: biology, physics and computer science $[21,22]$. The teacher is directly confronted with the demand of modern society to receive a high-quality education with promising directions.

\section{Results of the research}

It should be noted that thanks to advances in software, it is now possible to completely simulate any molecule, and, if there is additional time (based on extracurricular work) and technical capabilities, students can print out the works of their own ideas under the guidance of a teacher. Let's look at some examples of the introduction of 3D printing elements at various stages of studying a school chemistry course.

Let's consider the methodological elements of a lesson with elements of computer modeling and 3D printing in chemistry classes in the 11 th grade.

Title of the lesson: "3D chemical objects: from a molecule, a biochemical system to a chemical glassware".

Technology: Elements of computer chemistry in organic chemistry through integrated learning.

Topics covered:

1. "Nitrogen-containing organic compounds, their properties and applications";

2. "Allotropic modifications of the carbon atom";

3. "Chemistry of the DNA macromolecule";

4. "Chemical dishes in the laboratory: classification and purpose".

Joint goal: To create conditions for independent successful assimilation of new knowledge in various fields of organic chemistry by students of the 10th grade. 
Tasks by topic:

Developing:

$\checkmark \quad$ to contribute to the formation of the ability of students to find cause-and-effect relationships between phenomena;

$\checkmark \quad$ to develop students' thinking, namely the basic mental operations (analysis, synthesis, generalization, comparison, abstraction);

$\checkmark \quad$ to develop the creativity of students;

$\checkmark \quad$ to form a unified scientific picture of the world.

\section{Educational:}

$\checkmark \quad$ to form and develop communicative skills in monologue and dialogical speech in accordance with the norms of the language;

$\checkmark \quad$ education of an active personality.

Health-saving:

create a comfortable microclimate for each student.

Planned educational outcomes:

\section{Personal:}

- sustained cognitive interest and the ability to manage their cognitive activity;

- readiness to solve creative tasks;

- the need for social recognition; the basics of motivation for self-development and selfrealization;

- the adoption and implementation of the values of a healthy and safe lifestyle, the ability to carry out prevention, knowledge of basic health technologies.

Educational programs:

- to carry out independent selection of information sources and advanced search for information using the resources of libraries and the Internet in accordance with the goals and objectives;

- to analyze, critically evaluate and interpret information;

- to build logical reasoning, including the establishment of cause-and-effect relationships;

- to possess the skills of cognitive reflection as awareness of actions and thought processes, their results and grounds; the limits of their knowledge and ignorance, new cognitive tasks and means of achieving them.

Regulatory requirements:

- to find independently and to use effectively resource opportunities to achieve goals;

- to carry out cognitive reflection in relation to meta-subject actions of planning, control, evaluation in the process of solving educational and cognitive tasks.

Communication skills:

- to use speech to plan and regulate their activities adequately;

- to master the basics of communicative reflection as an orientation to the positions of other people, different from their own, understanding the relativity of assessments;

- to use adequately speech tools to solve various communicative tasks; knowledge of oral and written speech; to build a monological contextual statement;

- to display in speech (description, explanation) adequately, accurately and consistently the content of the actions performed, both in the form of loud socialized speech, and in the form of internal speech, both orally and in writing.

Subject areas:

- to confirm the existence of a genetic relationship between the organic substances of the studied classes by drawing up the equations of the corresponding reactions;

- to give examples of methods for obtaining simple substances;

- to analyze the composition, structure and properties of substances, applying the main provisions of chemical theories; 
- to explain the dependence of the reactivity of organic compounds on the structure of their molecules;

- to understand the role of chemistry in natural science, its connection with other natural sciences.

Students will also be able to:

- predict, depict and name molecular shapes (curved, linear, flat, tetrahedral);

- recognize the types of molecules;

- explore the geometry of molecules - the actual distances between the atoms in the molecule; the concept of the valence value of the angle; introduction to the concept of hybridization; the concept of the spatial (interplanar) angle.

- navigate the software to create 3D models of molecules;

- use ready-made structural files from an electronic database of free access on the Internet.

Methods:

1. Methods of knowledge introduction:

- summing up dialogue when setting a problem, making a plan, and finding a solution.

2. Methods of fixing new material:

- productive playback tasks;

- reproductive tasks for the development of skills and abilities.

3. Methods of primary knowledge control:

- introduction of computer chemistry elements through an electronic database and a program for object visualization.

\section{Resources:}

Computer and mouse for school children; online electronic databases of chemical objects; handout with a step-by-step description of the visualization of molecules; filamentous plastic and a $3 \mathrm{D}$ printer.

Lesson procedure:

1. Introduction to the topic of the lesson.

2. Demonstration of modern 3D printers in action.

3. To provide students time to discuss the chemical facility:

a) molecules (to determine its structural, physical and chemical properties (the number of links, electrons, etc.);

b) structure of the macromolecule (to determine its structural, chemical and biochemical properties (the number of links, electrons, etc.);

C) laboratory equipment (figure out a use for a specific task).

4. To demonstrate to the students how to work in online electronic database and in the visualization of the molecular models. To provide a handout.

5. To show students how to save their work in the final file.

6. Thematic tasks - a dialogue with students in the "Question-Answer" format; writing reaction equations; description of the chemical properties of nitrogen-containing compounds; description of the physical and chemical properties of allotropic carbon modifications; practical application; introduction to the classification of chemical dishes; correlation of the name-type of laboratory glassware.

Evaluation:

- The teacher tracks the stages of creating models of chemical objects in the software application;

- The teacher and students analyze the printed object (from a molecule, a biochemical system to a chemical dish) and work out thematic tasks for evaluation.

Within the framework of the "University - School" interaction, the ideas of applying the capabilities of 3D printing technology for models of molecules and chemical objects for further work with schoolchildren are implemented step by step. As a result, methodological 
recommendations, task sets, handouts on the following topics were prepared: "Allotropic modifications of the carbon atom"; "Nitrogen-containing organic compounds, their properties and applications"; "Chemistry of the DNA macromolecule"; "Chemical tableware in the laboratory: classification and purpose".

Figure $1(a-e)$ shows a computer model of a fullerene molecule and samples of printed forms of various chemical objects created by schoolchildren under the guidance of students and a chemistry teacher.

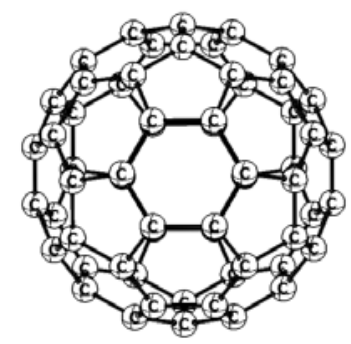

a)

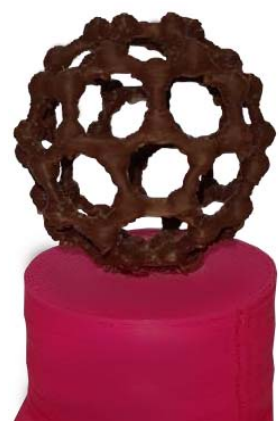

b)

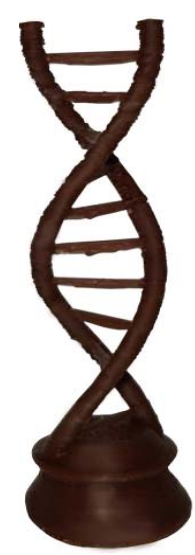

c)

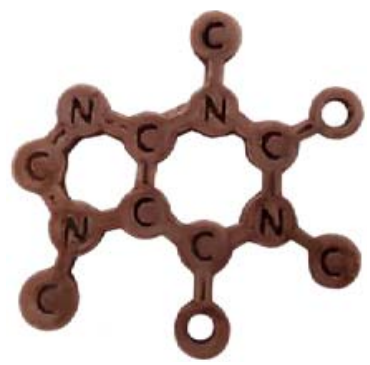

d)

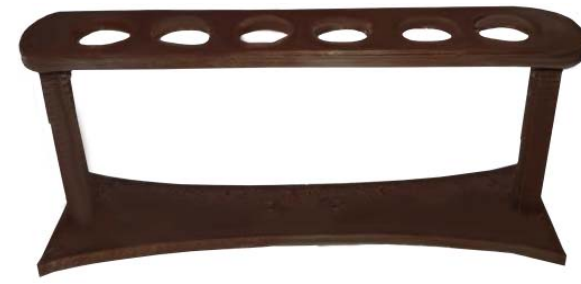

e)

Fig. 1. 3D samples: a) a computer model of $\mathrm{C}_{60}$ fullerene; b) a fullerene molecule on a stand; c) a DNA macromolecule; d) a flat structural model of caffeine; e) a test tube stand.

To visualize the models, the freely distributed Mercury program is used [23-25], then, in the MOPAC2016 computational program [26], the students additionally perform geometric optimization of molecules. The prepared models are exported to the STL format, intended for printing on a single-extruder 3D printer. The model of the DNA macromolecule and the tripod are taken from the database of three-dimensional printed objects https://3dprint.nih.gov/ [27, 28].

Prepared 3D-printed models of molecules are used in chemistry classes to improve the understanding of the existence of various allotropic modifications of carbon. Students effectively use these models in extracurricular project activities by (International competition among schoolchildren "My first business-2018", https://youtu.be/4FIDNC9qczI). 


\section{Conclusions}

Modern 3D printing technologies open up wide and promising opportunities in the field of creating model chemical objects, as well as laboratory complexes, providing an opportunity to improve the educational process.

As a result of the "UNIVERSITY - School" collaboration, the student receives new knowledge. He can demonstrate mastery of technological tools for accessing information, from modeling a chemical object "with their own hands" to performing a 3D printing procedure. The use of technologies and other information tools is necessary primarily for organizing the process and displaying knowledge in the form of a result, so that other students can see and use them for further study of the developed material. Promising directions open up for students and huge opportunities are provided to create chemical objects and entire model technological installations that are used in real conditions of the real world.

\section{References}

1. A.V. Kondrashova, Forms of interaction of school and university under modern conditions, International research journal, 09(63), 146-149 (2017)

2. M. Barak, Science teacher education in the twenty-first century: A pedagogical framework for technology-integrated social constructivism, Research in Science Education, 47, 283-303 (2017)

3. Yu.I. Shcherbakov, Interaction between the university and the school in modern conditions, World of Science, culture, education, 1(44), 105-107 (2014)

4. O.S. Sadomtseva, L.A. Dzhigola, V.V. Shakirova, Propedeutics of chemical knowledge in primary and secondary school students, Physics in school, S2, 186-189 (2020)

5. T. Trust, N. Woodruff, M. Checrallah et al., Educators' interests, prior knowledge and questions regarding augmented reality, virtual reality and $3 D$ printing and modeling, TechTrends (2021)

6. D. Gabel, Improving teaching and learning through chemistry education research: a look to the future, Journal of Chemical Education, 76(4), 548-554 (1999)

7. S. Ford, T. Minshall, Invited review article: where and how $3 D$ printing is used in teaching and education, Additive Manufacturing, 25, 131-150 (2019)

8. V. Kostakis, V. Niaros, C. Giotitsas, Open source $3 D$ printing as a means of learning: An educational experiment in two high schools in Greece, Telematics and Informatics, 32(1), 118-128 (2015)

9. M.J. Song, Learning to teach $3 D$ printing in schools: how do teachers in Korea prepare to integrate $3 D$ printing technology into classrooms?, Educational Media International, 55(3), 183-198 (2018)

10. A. Brown, $3 D$ printing in instructional settings: identifying a curricular hierarchy of activities, TechTrends, 59, 16-24 (2015)

11. M. Bower, M. Stevenson, A. Forbes et al., Makerspaces pedagogy - supports and constraints during $3 D$ design and $3 D$ printing activities in primary schools, Educational Media International, 57(1), 1-28 (2020)

12. E.G. Gordeev, V.P. Ananikov, Widely accessible $3 D$ printing technologies in chemistry, biochemistry and pharmaceutics: applications, materials and prospects, Russian Chemical Reviews, 89(12), 1507-1561 (2020) 
13. C.W. Pinger, M.K. Geiger, D.M. Spence, Applications of 3D-printing for improving chemistry education, Journal of Chemical Education, 1, 112-117 (2020)

14. B.C. Gross, J.L. Erkal, S.Y. Lockwood et al., Evaluation of $3 D$ printing and its potential impact on Biotechnology and the chemical sciences, Analytical Chemistry, 86(7), 3240-3253 (2014)

15. N.L. Dean, C. Ewan, J.S. McIndoe, Applying hand-held 3D printing technology to the teaching of VSEPR theory, Journal of Chemical Education, 93(9), 1660-1662 (2016)

16. E. Da Veiga Beltrame, J. Tyrwhitt-Drake, I. Roy et al., 3D Printing of Biomolecular Models for Research and Pedagogy, Journal of visualized experiments, 121, 5542755435 (2017)

17. I. Verner, A. Merksamer, Digital design and $3 D$ printing in technology teacher education, Procedia CIRP, 36, 182-186 (2015)

18. D. Marchak, I. Shvarts-Serebro, R. Blonder, Crafting molecular geometries: implications of neuro-pedagogy for teaching chemical content, Journal of Chemical Education, 3, 43-47 (2021)

19. M. Renner, A. Griesbeck, Think and print: $3 D$ printing of chemical experiments, Journal of Chemical Education, 97(10), 3683-3689 (2020)

20. D. Fourches, J. Feducia, Student-guided three-dimensional printing activity in large lecture courses: A practical guideline, Journal of Chemical Education, 96(2), 291-295 (2019)

21. J.D. Herron, S.C. Nurrenbern, Chemistry education research: improving chemistry learning, Journal of Chemical Education, 76(10), 1354-1361 (1999)

22. M. Huleihil, 3D printing technology as innovative tool for math and geometry teaching applications, IOP Conference Series: Materials Science and Engineering, 164(1), 12023-12030 (2017)

23. G.M. Battle, G.M. Ferrence, F.H. Allen, Applications of the cambridge structural database in chemical education, Journal of Applied Crystallography, 43, 1208-1223 (2010)

24. G.M. Battle, F.H. Allen, G.M. Ferrence, Teaching 3D structural chemistry using crystal structure databases: 1. An interactive web-accessible teaching subset of the Cambridge Structural Database, Journal of Chemical Education, 87, 809-812 (2010)

25. G.M. Battle, F.H. Allen, G.M. Ferrence, Teaching 3D structural chemistry using crystal structure databases: 2. Example teaching units that utilise an interactive webaccessible subset of the Cambridge Structural Database, Journal of Chemical Education, 87, 813-818 (2010)

26. J.P. Stewart, Stewart Computational Chemistry (2016)

27. A.V. Savchenkov, Designing Three-Dimensional Models That Can Be Printed on Demand and Used with Students to Facilitate Teaching Molecular Structure, Symmetry, and Related Topics, Journal of Chemical Education, 97(6), 1682-1687 (2020)

28. P.J. Paukstelis, MolPrint3D: Enhanced 3D Printing of Ball-and-Stick Molecular Models, Journal of Chemical Education, 95(1), 169-172 (2018) 